ISSN:2528-9527

E-ISSN : 2528-9535

YIl Year: 8

Cilt Volume: 9

Sayı Issue :16

Uluslararası Toplum Araştırmaları Dergisi

International Journal of Society Researches

Aralık December 2018

Makalenin Geliş Tarihi Received Date:20/10/2018

Makalenin Kabul Tarihi Accepted Date: 21/12/2018

\title{
Sanayi 4.0 Sürecinde Medyada Sektörel Dönüşüm
}

\author{
DOI: $10.26466 /$ opus.472798 \\ * \\ Birol Akgül ${ }^{*}$ - Zeynep Ayer
}

* Doç. Dr., Çanakkale Onsekiz Mart Üniversitesi, İletişim Fakültesi, Çanakkale/ Türkiye

E-Mail: birolakgul@comu.edu.tr ORCID: 0000-0002-0701-0928

"YL Öğr., Çanakkale Onsekiz Mart Üniversitesi, Sosyal Bilimler Enstitüsü Çanakkale/ Türkiye

E-Mail: ayerzeynep@gmail.com ORCID: 0000-0003-4107-0171

\section{Öz}

Bu çalışmada, özellikle makinelerin birbiriyle olan yeni iletişim metotların ve bu çerçevede insanların bilgi alabilmek ve süreci takip edebilmek adına kullanabileceği yeni yöntemleri göz önüne alarak medya sektörünün dördüncü sanayi devrimi kapsamında hangi konumda olacağı ve nasıl bir şekilde değişeceği üzerinde durulmuştur. Sanayi 4.0'ın, imalat ve hizmet sektörü başta olmak üzere, günlük hayatın pek çok alanında yeniliklere sebep olacă̆ 1 dikkate alındığında, medya sektöründe de önemli değişimler yaşanmasi; sektörün teknolojinin ağırlıkta olduğu bir gelişim göstermesi beklenmektedir. Bu çerçevede dördüncü sanayi devriminin getireceğgi yeniliklerin insanlara doğru bir şekilde aktarılması, bilgi kirliliğinin önlenmesi ve medya sektöründe yeniden yapılanmanın en etkin şekilde sağlanmasi; medya sektörünün yeni dijital dünyaya uyum să̆laması için neler yapıldiğı ve yapılması gerektiğ $i$ analiz edilmektedir. Bilgi bolluğunun yaşanacă̆ı Sanayi 4.0 döneminde doğru olan ve haber kaynă̆ kabul edilebilecek türdeki verilerin seçilebilmesi için veri gazeteciliği çalışmalarının yapılması tavsiye edilmektedir. Aynı zamanda veri gazeteciliği ile birlikte, okurun haber yapma sürecine dahil olması beklenmektedir. Gazetecilik sektörüne yönelik yapay zekanın tasarlanması, medyanın Sanayi 4.0'a uyumu sürecinde atılması gereken bir diğer önemli adım olarak görülmektedir. Yapay zekanın medyada kullanılması, Sanayi 4.0'ın kişiye özel üretim kriterinin medyada kişiye özel haber olarak yorumlanmasının önünü açacaktır. Buna ek olarak Sanayi 4.0'ı sunacağ teknik altyapıda istihdam edilecek nitelikli işgü̈ü̈n̈̈ yetiştirmek için, iletişim fakülteleri başta olmak üzere, eğitim politikasında değişim başlatılmalıdır. Medya okuryazarlı̆̆ı ve yeni medya derslerinin verilmesi, modern medya araçlarının kullanılması ile yükseköğrenim kurumlarında dönüşümün başlaması faydalı olacaktır. Çalışmada hem basılı hem de görsel medyadaki değişim incelenmekte, sektörde meydana gelen gelişmelerden örnekler ile Türk ve dünya medyastnın süreç içerisinde nerede olduğu ele alınmaktadır. Çalışmanın yöntemi olarak; literatür taraması, örnek olay incelemesi ve kurgulama yöntemleri birlikte kullanılmaktadır.

Anahtar Kelimeler: Medyada Yeniden Yapılanma, Medyada Dönüşüm, Sanayi 4.0, Nesnelerin Interneti ve Medya

OPUS (c) Uluslararası Toplum Araştırmaları Dergisi-International Journal of Society Researches ISSN:2528-9527 E-ISSN : 2528-9535

http://opusjournal.net 


\title{
Sectoral Transformation in Media in Industry 4.0 Process
}

\begin{abstract}
In this study, it was emphasized how the media industry would be in the position of the fourth industrial revolution and how it will change, especially considering the new communication methods of machines with each other and the new methods that people can use in order to get information and follow the process in this frame. Considering that Industry 4.0 will lead to innovations in many areas of our daily life, especially in the manufacturing and service sectors, there will also be significant changes in the media sector; it is expected that technology will make a significant progress. In this framework, the transfer of innovations brought forth by the fourth industrial revolution towards people, the prevention of information pollution and the restructuring of the media sector in the most efficient way, it is analyzed what needs to be done and what needs to be done so that the media industry can adapt to the new digital world. It is recommended that data journalism works should be carried out in order to select the type of data that is true and which can be accepted as source of news during the Industry 4.0 period where there will be an abundance of information. At the same time, along with data journalism, the reader is expected to be involved in the newsmaking process. The design of artificial intelligence for the journalism sector is seen as another important step that should be taken in the process of adaptation of the media to Industry 4.0. The use of artificial intelligence in the media, Industry 4.0 personalized production criteria will open the way to be interpreted as personal news in the media. In addition, in order to train the qualified workforce to be employed in the technical infrastructure to be offered by Industry 4.0, change in education policy, especially in communication faculties, should be initiated. Media literacy and the introduction of new media courses, the use of modern media tools and the transformation of higher education institutions will be useful. In the study, the changes in both print and visual media are examined, examples from the developments in the sector and where the Turkish and world media are in the process are discussed. As a method of working; literature review, case study and editing methods are used together.
\end{abstract}

Keywords: Restructuring in the Media, Transformation in the Media, Industry 4.0, Internet of Things and Media

OPUS (c) Uluslararası Toplum Araştırmaları Dergisi-International Journal of Society Researches ISSN:2528-9527 E-ISSN : 2528-9535

http://opusjournal.net 


\section{Giriş}

İlk defa 2011 yılında Almanya'da ortaya çıkan Sanayi 4.0, makine ve cihazların insana gerek olmadan nesnelerin interneti adı verilen sanal bir ağ üzerinden iletişim kurması ve süreci yönetmesi şeklinde çalışan yeni bir sanayi sistemidir. Esas olarak sanayi sektöründe ön plana çıkmakla birlikte, Sanayi 4.0'ın hizmet sektörünün de içinde bulunduğu birçok farklı alanda etkili olacak yeni bir sürecin kapısını aralayacağı öngörülmektedir.

Dördüncü sanayi devrimi, teknolojik gelişmelere öncülük etmiş ve farklı sektörlerde değişimi teşvik etmiştir. Gelişen teknolojiyle iletişim kolaylaşmış, dijitalleşme başlamış ve bilginin paylaşılmasına ortam hazırlanmıştır. Bilgi paylaşımı ve dijitalleşme internet ile birleştiğinde "büyük veri" adı verilen oldukça geniş bir bilgi ağı ortaya çıkmış ve doğru bilgi her zamankinden daha önemli bir rol kazanmıştır. Bilginin böylesi önemli hale geldiği bir süreçte, iletişim ve haber kavramları da farklı bir kimlik kazanma aşamasına girmiştir. İnternetin sağladığ1 bu değişim süreciyle birlikte haberin okunması ve yorumlanması süreçleri de insanlar tarafından farklı algılanmıştır. Bu kapsamda okurların haber alma eğilimleri ile gazetecilerin haber verme ve medya kurumlarının da haberleri sunma tekniklerine kadar bütün çalışma biçimleri değişime uğramıştır.

Üç ana bölümden oluşan bu çalışmanın birinci bölümünde dördüncü sanayi devrimi olarak da bilinen Sanayi 4.0 konusu ve Türkiye ile diğer ülkelerde konu ile ilgili yapılan çalışmalar incelenmiş, ikinci bölümde medya sektörü, medya sektörünün bugüne kadar geçirmiş olduğu değişim süreci ve dördüncü sanayi devrimindeki konumu üzerinde durulmuş, son bölümde de medya sektörünün Sanayi 4.0 kapsamında yeniden yapılandırılmasına yönelik görüş ve öneriler paylaşılmıştır.

\section{Sanayi 4.0}

Çalışmanın bu kısmında dördüncü sanayi devriminin açıklaması yapılmış ve kapsadığı alanlar ele alınmıştır. Bu çerçevede öncelikle dördüncü sanayi devriminin kavramsal incelemesi yapılmıştır. Ardından sanayi başta olmak üzere farklı sektörlerde etkisini hissettirmekte olan Sanayi 
4.0'1n ortaya çıkışı ve gelişim süreci analiz edilmiştir. Son olarak da dünyada ve Türkiye' de bu kapsamda geleceğe dair yapılan planlamalar üzerinde durulmuştur.

\subsection{Sanayi 4.0 Kavramı ve Kapsamı}

Son yıllarda teknolojinin ilerlemesiyle birlikte makineler gelişmiş, üretim süreci kolaylaşmış ve sistem daha modern bir form kazanmıştır. Bu dönemde klasik emek faktörler olan kol ve kas gücüne olan ihtiyaç neredeyse tamamen ortadan kalkarak, makineler hem kendilerini ve hem de üretim süreçlerini yalnız başlarına yönetmeye başlamışlardır(Taş vd. 2018). Bu gelişme sürecinin içinde bulunduğu son nokta olan Sanayi 4.0, cihaz ve makinelerin insandan bağımsız bir şekilde birbirine bağlanması ve üretim sürecini komuta etmesi olarak ifade edilmektedir.

Sanayi 4.0 üzerine yapılan çalışmalardan bahsetmeden önce terminoloji hakkında fikir sahibi olmak fayda sağlayacaktır. Sanayi 4.0 kapsamında kullanılan kavramlardan ilki olarak karşımıza çıkan nesnelerin interneti, dijital bir ağa ve internet bağlantısına sahip olan nesnelerin, sanal bir kimlik kazanması yoluyla, çevreleriyle fiziksel ve sosyal bağlamda iletişim halinde olmalarıdır (Davutoğlu, Akgül, Yıldız, 2017, 553). Doğru bir biçimde kumanda edildiği takdirde nesnelerin interneti, üretim maliyetlerini düşürebilmekte, geliri ve karlılığı artırabilmektedir. Bir diğer kavram olan Siber-Fiziksel Sistemler (Cyber-Physical Systems); üretim süreçlerindeki temel prensiplerin karma bir teknoloji tarafindan yönetildiği sistemlerdir (Siskon, 2017). 3 Boyutlu 3D Yazıcllar (3D printers) sanal bir veriyi, somut gerçek nesnelere dönüştüren cihazlardır (Siskon, 2017). Üretim bilgilerinin bilgisayara yüklenerek istendiği zaman ürüne dönüşmesini öngören bu sistem çerçevesinde, firmalar stok yapma gereği duymayacak ve bu da maliyeti azaltacaktır. Akıllı Fabrikalar (Smart Factories), dördüncü sanayi devriminin yapıtaşı olmakla birlikte devrimin getirdiklerinin somut olarak izlenebileceği bir ortamdır (Siskon, 2017). Otonom robotlar (Autonomous Robots), bir operatörün yönetiminde çalışabildikleri gibi, bir program aracılığıyla bağımsız olarak da çalışabilmektedir. Sistem Entegrasyonu (System Integration), birden fazla sistemin bir araya getirilerek tek bir sistem olarak çalışmalarını sağlamaktadır. Günümüzde sistemler, kendi içle- 
rinde çalışıp diğer sistemlerle de entegre olacak şekilde tasarlanmaktadır. Teknolojinin çığır açıcı düzeyde ilerlemesi ile birlikte internetin ve sosyal medya araçlarının gündelik hayata hakim olması sayesinde, bilgiye erişim büyük ölçüde kolaylaşmıştır. Bilgiye erişimin ve bilgi paylaşımının bu ölçüde yaygınlaşması, yararsız ve yanlış bilgi sorununu da aynı ölçüde artırmıştır. Bu yüzden tüm bu bilgi yığını, bilgi çöplüğü olarak nitelendirilmeye başlanmıştır. Çok fazla bilginin bulunduğu bu ortamdan gerçek ve güvenilir olanların ayıklanıp, saklanması mümkün olmuştur ki; bu da bizi, Büyük Veri (Big Data) kavramına götürmektedir. Bu bağlamda büyük veri; "toplumsal medya paylaşımları, ağ günlükleri, blog, fotoğraf, video, log dosyaları vb. gibi değişik kaynaklardan toparlanan tüm verinin, anlamlı ve işlenebilir biçime dönüştürülmüş biçimi" olarak tanımlanmaktadır. Bulut bilişim sistemi (Cloud Computing System) veya işlevsel anlamıla çevrim içi bilgi dağıtımı; bilişim aygıtları arasında ortak bilgi paylaşımını sağlayan hizmetlere verilen genel isimdir (Siskon, 2017). Artırılmış gerçeklik (Augmented Reality), gerçek dünyadaki çevrenin ve içindekilerin bilgisayar tarafından üretilen ses, görüntü, grafik ve GPS verileriyle zenginleştirilerek meydana getirilen canlı, doğrudan veya dolaylı fiziksel görünümüdür.

\subsection{Sanayi 4.0'a Yönelik Yapılan Çalışmalar}

Sanayi 4.0 kavramı ilk olarak 2011 yılında Hannover Fuarı'nda 4. Sanayi/Endüstri devrimi vurgusu ile ifade edildikten sonra günümüz işletme dünyasına Ekim 2012'de Bosch Şirketinde yönetici olan Siegfried Dias ve SAP AG firmasında üst düzey yönetici olan Hennig Kagermann tarafından oluşturulan çalışma grubunun hazırladıkları 4. Sanayi Devrimi öneri dosyasını Alman Federal Hükümeti'ne vermesi ve Nisan 2013 tarihinde Hannover Fuarı'nda bu çalışma grubunun Sanayi 4.0 raporunu sunmasıyla girmiştir (TÜSİAD, 2016). Rapora göre, Sanayi 4.0'ın başarıya ulaşabilmesi, donanım mimarisinin belirlenmesi ve standardizasyonu, karmaşık sistemlerin yönetilebilmesi, kapsamlı ve yüksek hızlı bir haberleşme altyapısının sağlanması, iş emniyeti ve güvenlik emniyetinin oluşturulması, çalışma organizasyonu ve tasarım, eğitim ve profesyonel gelişimin devamlılığı, mevcut mevzuatın uyarlanması, kaynakların verimli 
kullanılması referans olarak belirtilen sekiz önemli konunun gerçekleştirilmesini içermektedir (Landscheidt ve Kans, 2016).

Türkiye bilindiği üzere coğrafi olarak stratejik öneme sahip bir noktadadır. Türkiye verimli ve çeşitli doğal kaynaklara sahip, genç nüfus oranı yüksek; fakat aynı zamanda üretim konusunda dışa bağımlı ve işsizlik oranının yüksek olduğu bir ülkedir. Bu durumda Türkiye'nin kendine yeten bir ülke olması ve ayakta kalması için, ekonomik durumunu iyileştirmesi ve bunu muhafaza edecek politikalar uygulaması gerekmektedir.

Sanayi 4.0 adına Türkiye hakkında konuşmaya başlamadan önce, ülkenin teknolojik gelişimi ile sanayi ve işgücü profiline bakılmalıdır. $\mathrm{Bu}$ kapsamda TÜIK'in Hanehalkı Bilişim Teknolojileri Kullanım Araştırması, 2016 raporu incelendiğinde, Türkiye'de 16-74 yaş aralığında internet kullanan bireylerin oranı \%61,2 iken bu oran bilgisayar kullanımında \%51,9 olarak karşımıza çıkmaktadır. Çalışmaya göre yaklaşık on hanenin sekizi internet erişim imkanına sahip iken, hanelerin \%96, $9^{\prime}$ unda ise cep telefonu kullanılmaktadır. Teknoloji üretimi açısından TÜİK'in açıkladığ1 2017 yılı verilerine göre, orta yüksek teknolojili imalat sanayi ürünlerinin imalat sanayi ürünleri ihracatı içerisindeki payı \%33,6 iken bu oran ileri teknoloji ürünlerinde yalnızca \%2,7 olarak karşımıza çıkmaktadır. Teknoloji yoğunluğuna göre dış ticaret verilerinin ISIC Rev.3 sınıflaması içinde yer alan imalat sanayi ürünlerini kapsadığı dikkate alındığında, yüksek teknolojili ürünlerin Türk ihracatındaki payının çok düşük olduğunu söylemek doğru olacaktır.

Dünya Ekonomik Forumu'nun (WEF-World Economic Forum) en son yayınladığı rapora göre Türkiye, Küresel Rekabet Gücü Endeksi (Global Competitiveness Index) değerlerine dayanarak yapılan siralamada 7 üzerinden 4.42 puanla 137 ülke arasında 53. Sırada yer almaktadır. Raporda belirtilen gelişmiş ve gelişmekte olan ülkelerde inovasyonun 2009-2017 arasındaki gelişmesine bakıldığında Türkiye'nin 7 üzerinden 3,5 puan aldığı ve ABD, Almanya, Japonya, İngiltere gibi ülkelerin bir hayli gerisinde kaldığı görülmektedir. Rapora göre inovasyon kapasitesinde (capacity of innovation) 4.1 puanla 74., bilimsel araştırma kuruluşlarının kalitesinde (quality of scientific research institutions) $3.3 \mathrm{pu}-$ anla 100., şirketlerin Ar-Ge harcamalarında (company spendign on RED) 3.3 puanla 69., Ar-Ge üzerinde üniversite-sanayi işbirliğinde (university- 
industry collaboration on RED) 3.5 puanla 66., devletin ileri teknoloji ürünlerini temininde (goverment procurement of advanced technology products) 3.4 puanla 64 . Ve son olarak mühendis ve bilim insanlarının varlığında (availability of scientists and engineers) 4.3 puanla 49. Sirada yer almaktadır. Raporda üzerinde durulan bu göstergeler birlikte değerlendirildiğinde, Türkiye'nin inovasyon anlamında yetersiz kaldığı, Ar-Ge çalışmalarına gerekli bütçeyi ayırmadığı görülmektedir.

Mevcut durum göz önüne alındığında, Türkiye'nin acilen yeni politikalara geçmesi gerekmektedir. Bu kapsamda atılmış mevcut bir adım olarak TÜBİTAK tarafından hazırlanan "Yeni Sanayi Devrimi Akıllı Üretim Sistemleri Teknoloji Yol Haritası" adlı çalışma karşımıza çıkmaktadır. Söz konusu çalışmada, daha önceden belirlenmiş teknoloji gruplarına göre oluşturulan milli stratejik hedefler ile bu hedeflere ulaşılması için yapılması gereken çalışmalar ve altyapıya yönelik olarak Ar-Ge projeleri tasarlanmıştır. Yeni Sanayi Devrimi Akıllı Üretim Sistemleri Teknoloji Yol Haritası' nda belirtilen 10 hedef şu şekildedir:

1. Servis Bulut Platformu, Güvenlik ve Mahremïyet (Cloud Platform Services, Security and Privacy)

2. Büyük Veri Analitiği (Big Data Analytics) :

3. Siber Güvenlik Çözümleri (Syber Security Solutions)

4. Modelleme ve Simülasyon Çözümleri (Modelling and Simulation Solutions):

5. Endüstriyel Nesnelerï İnterneti Platformu (The Platform for the Internet of Industrial Things)

6. M2X Yazılım ve Donanımları (MX2 Software and Equipments) :

7. Yenilikçi Sensörler (Innovative Sensors) :

8. Robot, Otomasyon, Ekïpman, Yazılım ve Yönetïm Sïstemlerï (Robot, Automation, Equipment, Software and Management Systems) :

9. Eklemelï İmalat Malzemeleri, Ekïpmanlar, Yazllimlar (Additive Manufacturing Materials, Equipments, Software)

10. Akıllı Fabrika Sïstemlerï (Smart Factory Solutions)

\section{Sanayi 4.0’a Göre Medya Sektörü}

Sanayi 4.0 ile birlikte bilgi ve iletişimin öneminin artacağı beklentisi, medya sektörünün bu çerçevede nasıl bir rol alacağı hakkında merak 
uyandırmaktadır. Temel amacı haber yapmak olan medya sektörünün dördüncü sanayi devriminin sağlayacağı dijital ortama uyum sağlaması beklenmektedir. Çalışmanın bu kısmında ilk olarak medya sektörünün yapısı ve kapsamı üzerinde durulmuş, ikinci bölümde medya sektörünün Sanayi 4.0 ortaya çıkana kadar olan dönemdeki gelişimi incelenmiş, devamında ise dünyada ve Türk medyasında dördüncü sanayi devrimi kapsamında meydana gelen değişimler ve geleceğe dair öngörüler üzerinde durulmuştur.

\subsection{Medya Sektörünün Yapısı ve Kapsamı}

Günlük hayatta sıkça karşılaştığımız medya, gazete, dergi, radyo, televizyon ve internet gibi çeşitli kitle iletişim araçlarını kapsayan bir kavramdır. Medya esasen, insanlar arasındaki iletişimin kurulabilmesi için gerekli olan altyapı ile bu iletişimin kurulduğu ortamı ifade etmektedir.

Medyanın kapsamı içinde yer alan kitle iletişim araçları, temel olarak haber alma ve yayma ihtiyacına bağlı olarak ortaya çıkmıştır. Bu kapsamda medyanın ana işlevlerinden birinin haber verme olduğu söylenebilir. Haber alma ihtiyacinın bir sonucu olarak haber mektupları ortaya çıkmış ve ekonomik, toplumsal ve siyasi sebeplerle yaygınlaşmıştır (Durmuş, 2017). Diğer taraftan medya, hizmet sektörünün içinde yer alarak iktisadi anlamda da bir işleve sahip olmaktadır. İçinde bulunduğumuz ekonomik koşullarda medya, reklam gelirleriyle beslenen, insanları yapmış olduğu yayınlar aracılığıyla yönlendirebilen büyük bir sektör konumundadır. Medya aslında haber verme işlevinin ötesinde, bugün ekonomide önemli roller üstlenen bir aktör konumundadır. Kısacası medya genel anlamda iletişim araçlarını ve haber vermeyi ifade etmekle birlikte, başlı başına iktisadi bir rolü de olan bir sektörü ifade etmektedir.

Medya sahip olduğu imkanlar neticesinde toplumu bir arada tutma ve haber alışverişini hızlandırma sorumluluklarını üstlenmektedir. Ancak bilgi alışverişinin hızlanması, birtakım problemleri beraberinde getirmektedir. Günümüzde medya sektöründe gerçek ve tüzel kişilere ait bilgilerin gizliliği kritik öneme sahiptir. 6698 sayılı Kişisel Verilerin Korunması Hakkında Kanun, kişisel verilerin işlenmesinde başta özel hayatın gizliliği olmak üzere kişilerin temel hak ve özgürlüklerini korumak ve kişisel verileri işleyen gerçek ve tüzel kişilerin yükümlülükleri ile 
uyacakları usul ve esasları düzenlemektedir. Bu kanun kapsamında medya sektörü aktörlerine önemli görevler düşmektedir. Medyanın varlık nedeni olan iletişim özgürlüğü ve bu özgürlügün kullanılması durumunda, ilgili kanun çerçevesinde diğer kişi ve kurumların şahsi hak ve özgürlüklerinin ihlaline meydan verilmemelidir.

Günümüzde artık iletişim araçlarını kullanmakta olan herkes medyanın aktif birer aktörü konumundadır. Medya sektöründe profesyonel anlamda yer almayan herkes, çok kolay bir şekilde interneti kullanarak iş yapabilmekte, internet üzerinden kazanç sağlayabilmekte, yayın yapabilmekte ve tanınırlığını artırabilmektedir. Dolayısıyla medya sektörünün kapsadığı alan günden güne genişlemektedir.

\subsection{Medya Sektörünün Dördüncü Sanayi Devrimi Öncesi Dönemdeki Yapis1}

Medya sektöründe kendini göstermeye başlayan dönüşüm süreci, bilgi teknolojilerindeki ilerleme ve globalleşme çabalarının etkisiyle medyanın baştan sona yeni bir yapıya girmekte olduğunu göstermektedir. Teknolojik, ekonomik ve sektörel anlamda bir nevi kabuk değiştirmeye başlamış olan medya sektörü, çalışma şartları, iş koşulları ve sektördeki bire bir ilişkiler anlamında farklılıklar doğmasına ortam hazırlamıştır.

Medya sektöründeki değişime genel hatlarıyla bakıldığında, Türkiye'de neredeyse 1980 'e kadar medya sektöründe aile şirketlerinin hakim olduğu, daha sonraki süreçte ise teknolojik şartların değişmeye başlaması ve Türkiye'nin ekonomik anlamda içinde bulunduğu sıkıntılı durum sebebiyle medya sektörü dişında faaliyet gösteren büyük kuruluşların medya alanında rol almaya başladığı görülmektedir. 1990 yılında kurulan ilk özel televizyon istasyonunun yayına başlaması ve görsel yayınc1lıkta devlet tekelinin ortadan kalkması ile birlikte, medya sektörü plansız ve kontrolsüz bir büyüme trendine girmiştir (T.C. Başbakanlık BasınYayın ve Enformasyon Genel Müdürlüğü, 2013: 10). Bu olay ile birlikte medya sektörü, yatay ve dikey tekelleşmeler ile karşı karşıya gelmiş, kartel oluşumları ve promosyona dayanan satış teknikleri ile Türk medyası birkaç büyük medya grubunun kontrolü altına girmiştir. Dolayısıyla bu dönemde medyada tekelleşme eğilimleri giderek artış göstermiştir. 
Türkiye'de gözlenen mevcut piyasa yapısının temel sebebi, çapraz tekelleşmeyi engelleyen yasaların eksikliğidir. Çapraz tekelleşmede, farklı medya kollarında faaliyet gösteren kuruluşlar tek bir kişi ya da bir medya grubunun kontrolü altında faaliyet göstermektedir. Çapraz medya sahipliği, aynı sermaye sahipliğinin farklı medya alanlarında ve diğer alanlarda mülkiyet sahibi olması da çapraz medya yoğunlaşması olarak tanımlanmaktadır (Kuyucu, 2013: 149). Türkiye'de neredeyse her medya grubunun farklı alanlarda çalışmaları ve yatırımları mevcut olup, medya dışında faaliyet gösteren büyük kuruluşların da gelecekte medya sektöründe rol alması olasıdır.

\subsection{Medya Sektörünün Sanayi 4.0 Kapsamında Değişimi}

20. yüzyılda hayatımıza giren internet, medya sektörünü de etkisi altına almıştır. 1950'ye kadar gazete ve dergilerin ön planda olduğu medya sektörü, 1950' den sonra radyo, televizyon ve internet gibi görsel iletişim araçlarının etkisi altındadır. Teknolojinin gelişmesiyle birlikte medya sektörü de dijital bir form kazanmaya başlamıştır. Kitle iletişim araçları çağı olarak da adlandırılan ve halihazırda içinde bulunduğumuz dönemde, medya sektörünün kapsadığı araçların internet üzerinden yönetilmesi söz konusudur. Bilgisayar ve internetin medyadaki kullanımının artmasıyla birlikte, medya sektörü yapısal bir değişim sürecine girmiştir.

Dördüncü sanayi devriminin medya sektörüne sağlayacağı en büyük avantaj, sahiplik yapısının değişmesidir. Bu değişimin temelinde esasen 2000 yılı ve devamında ortaya çıan teknolojik gelişmelerin etkisi bulunmaktadır. Teknolojinin gelişmesiyle birlikte medya kuruluşlarının sahiplik algısı değişmiş, büyük miktarda sermayeye duyulan ihtiyaç yerini bilgi ve donanıma bırakmaya başlamıştır.

Kitle iletişim araçları çağı olarak da adlandırılan ve içinde bulunduğumuz dönemde, artık medya sektöründe söz söyleyebiliyor olmanın ana şartı sermaye sahibi olmak değildir. Bu dönemde yetenek, hayal gücü, pratik düşünebilme yeteneği ve zeka önem kazanmaya başlamıştır. Dolayısıyla büyük sermayeye sahip medya kuruluşlarından farklı bir prensiple çalışan medya aktörleri ortaya çıkmaya başlamıştır. Teknolojiyi aktif olarak kullanabilen, bireysel çalışma ile sanal ortamdan kazanç 
sağlayabilen bu aktörler, medyanın gelecekte nasıl bir form alacağı hakkında önemli ipuçları vermektedir.

İnternet üzerinden yapılan işler, neredeyse sıfır maliyetle kurulabilen ve iki - üç kişinin çalışmasıyla ayakta tutulabilen girişimlerdir. Maliyetin düşmesinin temelinde esasen iş yeri açmaya ihtiyaç duyulmaması, işi devam ettirmek için temel bir bilgisayar ve internet bağlantısı dişında ekstra bir maddi masrafının olmaması yatmaktadır. Buna ek olarak, çalışan sayısının çok olmaması ve herhangi bir organizasyon yapısına ihtiyaç duyulmaması da maliyetleri ciddi derecede düşürmektedir.

\section{Medya Sektörünün Dördüncü Sanayi Devrimi'ne Göre Dönüşümü ve Yeniden Yapılanmasına Yönelik Öneriler}

Sanayi 4.0, nesnelerin interneti ve siber fiziksel sistemler aracılığıyla imalattan hizmet sektörüne kadar farklı alanlarda sanal bir sürece işaret etmektedir. Bilgiye ve habere ulaşmanın kolaylaşmasıyla birlikte medya sektörünün de bu kapsamda internet hakimiyetine girmesi beklenmektedir. Oxford Üniversitesi'ne bağlı Reuters Enstitüsü'nün Dijital Haber Raporu 2016 başlıklı araştırmasına göre 26 ülkede ankete katılanların yüzde 51'i sosyal medyayı haftalık haber kaynağı olarak kullanmaktadır. 18-24 yaşları arasındaki gençlerin yüzde 28 'i ana haber kaynağı olarak sosyal medyayı tercih etmekte; bu oran televizyonu seçenlerde ise $\% 24$ olarak açıklanmıştır. Dolayısıyla önümüzdeki dönemde sosyal medyanın medyadaki rolünün daha da önem kazanacağını söyleyebiliriz.

Sanayi 4.0 ile birlikte internetin ve dijital verinin medyadaki hakimiyetinin artacağı beklentisi, bizleri medya sektörünü bu yeni sürece adapte edecek politikaları araştırmaya teşvik etmektedir. Bu kapsamda yapılabilecek şeylerden birincisi veri gazeteciliği üzerine çalışmaktır. Günümüzde yaşanmakta olan bilgi bolluğu, iletişimin ve doğru habere ulaşmanın önemini artırmıştır. Bu kapsamda veri gazeteciliği, Data Journalism Handbook (Veri Gazeteciliği El Kitabı) isimli kitapta, veri ile gazetecilik yapmak olarak tanımlanmaktadır. Başka bir ifadeyle, her türlü gazetecilik faaliyetinde veriyi düzenleyip, filtreleyip günümüz dünyası için anlamlı hale getirmektir. Veri gazeteciliğinin kullanmakta olduğu raporlama tekniği ile okuyucu süreç içerisine dahil olabilmekte ve veriyi anlamlandırarak yeni kavramsal ilişkiler ortaya koyabilmektedir. 
İkinci olarak medya sektörüne yönelik yapay zeka geliştirme çalışmaları dikkat çekmektedir. Burada normal bir robotta kullanılan yapay zekadan farklı olarak, sanal ortamdan haber olabilecek güncel ve doğru veriyi filtreleyip bunu haber yapabilme özelliği barındıran yapay zeka aynı zamanda bu işlemi herhangi bir komuta gerek duymadan devamlı yapabilmektedir. Konuyla ilgili olarak Google'ın finanse ettiği bir çalışma olan "The Digital News Initiative" isimli bir proje mevcuttur. Söz konusu projeye göre medya sektörüne yönelik tasarlanmış olan yapay zekanın, büyük veri üzerinden verileri toplaması ve yerel medya kanalları için ayda otuz bin haber üretmesi planlanmaktadır.

Medyanın yeniden yapılanması kapsamında iletişim eğitimi veren kurumlarda da yapılması gereken çalışmalar bulunmaktadır. Bu çerçevede özellikle iletişim fakültelerinde devlet ve sanayinin desteği önem kazanmaktadır. Medya okuryazarlığının geliştirilmesi için çalışmalar yapılmalı, öğrencilerin giderek dijitalleşen medyayı anlayabilmesi, yorumlayabilmesi ve haber üretebilmesi teşvik edilmelidir. Burada gerek fiziksel gerek maddi anlamda öğrencilerin çalışmalarına uygun ortam sağlayabilmek adına kütüphane ve laboratuvar olanakları iyileştirilmeli, kütüphanelere kaynak desteği verilmeli, projeler teşvik edilmelidir.

\section{Sonuç}

Sanayi 4.0 henüz birkaç yıldır adından bahsedilmekte olan bir kavram olsa da, imalat ve hizmet sektörleri başta olmak üzere hayatımızın farklı alanlarını etkisi altına almaya başlamıştır. Günümüzde bilgiye ulaşmanın kolaylaşması ve bilgi bolluğunun yaşanması, doğru bilginin ve güvenilir kaynaklara dayanana haberciliğin önemini artırmıştır. Haber kaynağının çoğunlukla internet ve sosyal medyaya dayanması ve internet gazeteciliğinin yaygınlaşması, medya sektörünün de Sanayi 4.0'dan önemli derecede etkileneceği ve yapısal anlamda değişime uğrayacağ söylenebilir. Bu kapsamda medya sektörünün Sanayi 4.0 kapsamında yeniden yapılanmasına yönelik olarak birtakım değişiklikler yapılmalıdır. Bunlar temel olarak veri gazeteciliğgi üzerine çalışmalar yapılması, medya sektörüne yönelik olarak özel yapay zeka tasarlanması ve eğitim alanında, iletişim eğitimi veren yükseköğrenim kurumları başta olmak üzere, eğitim anlayışında bir değişime gidilmesidir. 
EXTENDED ABSTRACT

\title{
Sectoral Transformation in Media in Industry 4.0 Process
}

\author{
* \\ Birol Akgül - Zeynep Ayer \\ Çanakkale Onsekiz Mart University
}

Today, as a strategic concept, Industry 4.0 is fully implemented, it is expected that there will be a wide change in overall economic structure in the world. The fact that technology and internet have shown itself in the media in the last fifty years gives hints that the media will change significantly during the Industry 4.0 process, where virtual data and internet-based systems will be used. The aim of this study is to discuss the expected transformation of the media in the Fourth Industrial Revolution. Case study and fictional analysis methods were used in the study.

Industry 4.0 refers to the last point of the development of the industry from the 18th century to the present, the Fourth Industrial Revolution. The new era, in which digital technologies will be used intensively, is also called as the digital age. In addition to developed countries such as Germany, USA and UK, nowadays, there are extensive studies on Industry 4.0 around the world.

The concept of Industry 4.0 was first mentioned at the Hannover Fair in 2011 with the emphasis of the 4th Industrial / Industrial revolution. The 4th Industrial Revolution was submitted to the Federal Government of Germany with the proposal file and in April 2013, this working group presented the Industry 4.0 report at the Hannover Fair. Success of Industry 4.0, determination and standardization of hardware architecture, management of complex systems, provision of comprehensive and highspeed communication infrastructure, establishment of safety and security safety, work organization and design, continuity of education and professional development, adaptation of existing legislation, efficient of 
resources the implementation of eight important issues referred to as reference.

According to a report published by the World Economic Forum's latest Turkey, the Global Competitiveness Index (Global Competitiveness Index), based on the value of the ranking made out of 7 points between the 4:42 137 countries situated next 53. When the report looked at the development between developed and developing countries specified in innovation 2009-2017 Turkey's received 3.5 points out of 7 and the USA, Germany, Japan, countries such as the UK shows that a great deal remains behind. According to the report, capacity of innovation is rated 74 with 74 points, quality of scientific research institutions with a score of 3.3 and 100 with company spendign on R \& D. university-industry collaboration on $\mathrm{R} \& \mathrm{D}$ with 3.5 points 66 . goverment procurement of advanced technology products, with a score of 3.4. is ranked 49th in points. Rinse Taken together, these indicators on the report, Turkey's is inadequate in terms of innovation, $\mathrm{R} \& \mathrm{D}$ work shows that the necessary budget allocations. Taking the current situation into consideration, Turkey needs to urgently go to the new policy. In this context,. New Industrial Revolution Intelligent Production Systems Technology Road Map Har prepared by TUBITAK is a current step. In this study, R \& D projects have been designed for the national strategic targets created according to the predetermined technology groups and for the works to be achieved to achieve these targets and for the infrastructure.

The expectation that the importance of information and communication will increase together with Industry 4.0 arouses interest in the role of media sector in this framework. The media sector, whose main objective is to make news, is expected to adapt to the digital environment provided by the fourth industrial revolution.

The media, which we frequently encounter in daily life, is a concept that includes various media such as newspapers, magazines, radio, television and internet. The media mainly refers to the environment in which this communication is established with the infrastructure necessary for the communication between people. Nowadays, everyone who is using communication tools is an active actor of the media. Anyone who is not a professional in the media sector can do business very easily by using the internet, can gain profit on the internet, can broadcast and 
can increase their recognition. Therefore, the area covered by the media sector is expanding day by day.

The transformation process, which has begun to show itself in the media sector, shows that the media are entering a new structure from the beginning to the end thanks to the progress in information technology and the efforts of globalization. The media sector, which has started to change some technological, economic and sectoral shells, has created an environment for differences in terms of working conditions, working conditions and one-to-one relations in the sector. The main reason of the current market structure observed in Turkey is the lack of laws to prevent cross monopolization. In crossmonopolization, organizations operating in different media branches operate under the control of a single person or a media group. Crossmedia ownership is defined as the cross-media concentration of ownership of the same capital in different media and other areas. In Turkey is almost all media groups in different fields of work and investment of existing, large organizations operating outside the media is also possible to take part in the media industry in the future.

In parallel with industrial revolutions, the need for labor has decreased over time. This decrease was not limited to the industrial sector. Mechanization and automation have also shown in the agriculture and service sector. The reflection of mechanization and automation on the media varies slightly from the service sector. With the development of technology, modern journalism techniques and new generation mass media are used in the media sector. Due to the nature of the media sector, automation can be applied to a certain point. Since the subject, interest and basic source of the media is human, it is not possible to think of a media independent of human. In this context, Media 4.0 can be interpreted as the human being actively participating in the process, but adapting to a new infrastructure where the working method and organizational structure of the media institutions will be used predominantly in the use of digital methods.

The expectation that the internet and digital data will dominate the media together with Industry 4.0 encourages us to investigate the policies that will adapt the media sector to this new process. The first thing that can be done in this context is to work on data journalism. Today, the 
abundance of information, communication and accurate news has increased the importance of reaching. In this context, data journalism is defined as doing journalism with Data Journalism Handbook. With the reporting technique used by data journalism, the reader can be included in the process and can make new conceptual relations by making sense of the data. Secondly, the development of artificial intelligence for the media sector is noteworthy. Unlike the artificial intelligence used in a normal robot here, news from the virtual environment that can filter the current and accurate data that feature the ability to make news with artificial intelligence at the same time can do this without the need for any command.

In the context of the restructuring of the media, there are studies to be done in the institutions providing communication education. In this framework, the support of the state and industry is gaining importance especially in the communication faculties. Efforts should be made to improve media literacy, and students should be encouraged to be able to understand, interpret and produce news digitally.

Industry 4.0 is a concept that has been put forward at the Hannover Fair of Germany in 2011 and is now being discussed and studied globally. The industry has so far gone through three stages: the mechanization of the production process, the use of electricity in production and the automation of production. In the last stage known today as Industry 4.0, production is based on cyber physical systems. A virtual copy of the real world with cyber physical systems is created and all production mechanisms are remotely controlled. In this context, it can be said that the need for people will decrease day by day. Industry 4.0 is expected to open the door of a new era in the media, which will be called Media 4.0. Within the scope of Media 4.0, it is recommended to carry out very journalistic studies, use of artificial intelligence in journalism and revise education policies, especially in institutions providing communication education. 


\section{Kaynakça/References}

Dağ, P., (2017). Data journalism handbook. http://www.academia.edu/16286677/GAZETEC\%C4\%B0L\%C4\%B0\%C4\%9E\%C4\%B0N_GE LE-

CE\%C4\%9E\%C4\%B0_VER\%C4\%B0_GAZETEC\%C4\%B0L\%C4\% B0\%C4\%9E\%C4\%B0_-P\%C4\%B1nar_Da\%C4\%9F_Ekitap , Erişim Tarihi: 29.09.2017

Davutoğlu, N., Akgül, B. ve Yıldız, E., (2017). İşletme yönetiminde Sanayi 4.0 kavramı ile farkındalık oluşturarak etkin bir şekilde değişimi sağlamak. Akademik Sosyal Araştırmalar,52, 544-567.

Durmuş, B. T).2017). Matbaa teknolojisinin Osmanlı devletine giriş koşulları ve tartışmalar. Gümüşhane Üniversitesi İletişim Fakültesi Elektronik Dergisi, 5(2), 950-968

Kişisel Verilerin Korunması Hakkında Kanun. http://www.resmigazete.gov.tr/eskiler/2016/04/20160407-8.pdf Erişim Tarihi: 01.11.2017

Kuyucu, M (2013). Bâb-ı Ali'den tablet gazetelere basın işletmeciliği. iletişim ve diplomasi (1) http://www.iletisimvediplomasi-.com/bab-ialiden-tablet-gazetelere-basin-isletmeciligi/ Erişim Tarihi: 30.10.2017

Landscheidt, S., ve Kans, M (2016) automation practices in wood product industries: Lessons learned, current practices and future perspectives. in The 7th Swedish Production Symposium SPS, 25-27 October, 2016, Lund, Sweden. Lund University.

Reuters Institute, (2016). Digital news report 2016. http://reutersinstitute.politics.ox.ac.uk/sites/default/files/research/files/Digital\%2520News\%2520Report\%25202016.pdf Erişim Tarihi: 02.11.2017

Siskon (2017). Sanayi 4.0 ile ilgili kavramlar ve açıklamaları. http://www.siskon.com.tr/haberler/sanayi-4.0-ile-ilgili-

kavramlar-ve-aciklamalari/ Erişim Tarihi: 01.09.2017 
Taş, H. Yunus, Demirdöğmez M. ve Küçükoğlu, M., (2018). Endüstri 4.0'ın çalışma hayatına ve girişimciliğe muhtemel etkileri. 2. Uluslararası Gap İsletme Bilimleri ve Ekonomi Kongresi, 4-7 Ekim, 2018, Ss.94-104- 6

TC. Başbakanlık Basın-Yayın ve Enformasyon Genel Müdürlüğü (2013) Bir bakışta Türk medyası. http://www.byegm.gov.tr/uploads/docs/Bir_Bakista_Turk_Medyasi_TR.pdf Erişim Tarihi: 03.11.2017

TÜİK, (2017). Hanehalkı bilişim teknolojileri kullanım araştırması, 2016. http://www.tuik.gov.tr/PreHaberBultenleri.do?id=21779 Erişim Tarihi: 01.10.2017

TÜSİAD (2016). Türkiye'nin küresel rekabetçiliği için bir gereklilik olan Sanayi 4.0 gelişmekte olan ekonomi perspektifi. http://www.tusiad.org/indir/2016/sanayi-40.pdf Erişim Tarihi: 10.02.2017.

WEF (2017). The global competitiveness report 2016-2017. https://www.weforum.org/reports/the-global-competitiveness-report-20162017-1 Erişim Tarihi: 02.10.2017

\section{Kaynakça Bilgisi / Citation Information}

Akgül, B. ve Ayer, Z. (2018). Sanayi 4.0 sürecinde medyada sektörel dönüşüm. OPUS-Uluslararası Toplum Araştırmaları Dergisi, 9(16), 23102327. DOI: $10.26466 /$ opus. 472798 